\title{
Morphology of immature stages of Prostomis mandibularis (Coleoptera: Tenebrionoidea: Prostomidae)
}

\author{
IsABEL SCHUNGER ${ }^{1}$, RoLF G. BEUTEL ${ }^{2}$ and RALF BRITZ ${ }^{1}$ \\ ${ }^{1}$ Lehrstuhl für Spezielle Zoologie, Eberhard-Karls Universität Tübingen, Auf der Morgenstelle 28, D-72076 Tübingen, Germany; \\ e-mail: ralf.britz@uni-tuebingen.de \\ ${ }^{2}$ Institut für Spezielle Zoologie und Evolutionsbiologie, Friedrich-Schiller-Universität, Ebertstr. 1, D-07743 Jena, Germany
}

Key words. Prostomis mandibularis, Prostomidae, Tenebrionoidea, SEM, morphology, larva, pupa, larval head anatomy, systematic position

\begin{abstract}
Structural features of larvae and pupae of Prostomis mandibularis are described in detail. Larval features are discussed with respect to their functional and phylogenetic significance. The distinct asymmetry of the larval head, absence of stemmata, presence of a sensorial field on antennomere III, and elongated and broadened mandibles of pupae and adults are autapomorphies of Prostomidae. The placement of Prostomis within Tenebrionoidea is suggested by the posteriorly diverging gula with well developed gular ridges and the anterior position of the posterior tentorial arms. Affinities of Prostomidae with the pythid-pyrochroid-lineage is supported by the pad-like structure of the maxillary articulatory area, the abdominal tergite IX extending to the ventral side of the segment, and the strongly pronounced prognathous condition. Presence of a distinct molar tooth is a derived feature shared by Prostomidae, Pythidae, Pyrochroidae, Inopeplidae and Othniidae. A thorax narrower than the head and the abdomen, and a plate-like abdominal segment IX, which articulates with segment VIII, are possible synapomorphies of Prostomidae, Boridae, Mycteridae and Pyrochroidae. The strongly flattened, prognathous head and the strongly flattened body of larvae of Prostomidae are correlated with their habits of boring in wood of decaying logs.
\end{abstract}

\section{INTRODUCTION}

Prostomidae is a small family of beetles with an almost world-wide distribution (absent in South America). In Europe, they are represented by only one species, Prostomis mandibularis (Fabricius, 1801), which also occurs in the Caucasus, Elburs Mountains and North America (Fleischer, 1919; Schawaller, 1993). It is considered rare in Central Europe, whereas it appears to be more common in northern and eastern Europe. Further species of the genus Prostomis Latreille, 1829 are described from the southern and eastern Palearctic region (Turkey, Himalayas, Japan), the Oriental region (Southeast Asia), the Australian region (Australia, New Caledoniaen) and from South Africa (Fleischer, 1919; Schawaller, 1991, 1992 , 1993, 1994). The second genus Dryocora Pascoe, 1868 occurs only in New Zealand, Tasmania and Sri Lanka.

Different systematic placements were proposed for Prostomidae by different authors. In most older studies, Prostomis was treated as a genus of Cucujidae and therefore placed within Cucujoidea (Böving \& Craighead, 1930; Crowson, 1953; Curtis, 1854; Erichson, 1848; Oliff, 1884; Reitter, 1911). A closer affinity with Heteromera (= Tenebrionoidea) was hypothesized by Wilson (1930), based on wing venation and shape of the aedeagus. However, as he could not support this possible relationship with further characters, he left the family within Cucujoidea. Crowson (1955) initially considered Prostomidae as a cucujoid family, even though he discussed larval characters (blunt, rounded mala, absence of the prostheca), which suggest a closer relationship of Prostomidae with Inopeplidae and Hemipeplidae, and therefore a placement within Heteromera. In a later study, he placed Prostomidae within Tenebrionoidea (Crowson, 1967). Lawrence (1977) suggested, that Prostomidae, together with Oedemeridae, could have evolved as an offspring of Crowson's "synchorid-cephaloid-zopherid lineage". Lawrence \& Newton (1982) also treated Prostomidae as a tenebrionoid family. They discussed affinities of larval head structures of Prostomidae, Oedemeridae and Cephaloidae, but placed Prostomidae near Colydiidae based on the condition of the procoxal-cavity and the aedeagus. In contrast to that, Young (1991) considered Inopeplidae, Salpingidae or Othniidae as closest relatives of Prostomidae.

Problems with the systematic placement of Prostomidae are partly due to lack of detailed anatomical data. Internal structures of the larva have not been described so far and internal features of other tenebrionoid larvae are also largely unknown. To fill this gap, a detailed account of structural features of the larva of a species of Prostomis is provided, and the pupa is described for the first time. The morphological data are discussed with respect to their function and possible systematic implications. The proposed phylogenetic hypothesis has to be considered as preliminary. A cladistic analysis was not carried out as this would have required the examination of larval representatives of a large number of families of Cucujoidea and Tenebrionoidea. This would have been beyond the scope of this primarily morphological contribution.

\section{MATERIAL AND TECHNIQUES}

During field studies in 2000, larvae and adults of Prostomis mandibularis were encountered regularly in the Bannwald Faul- 

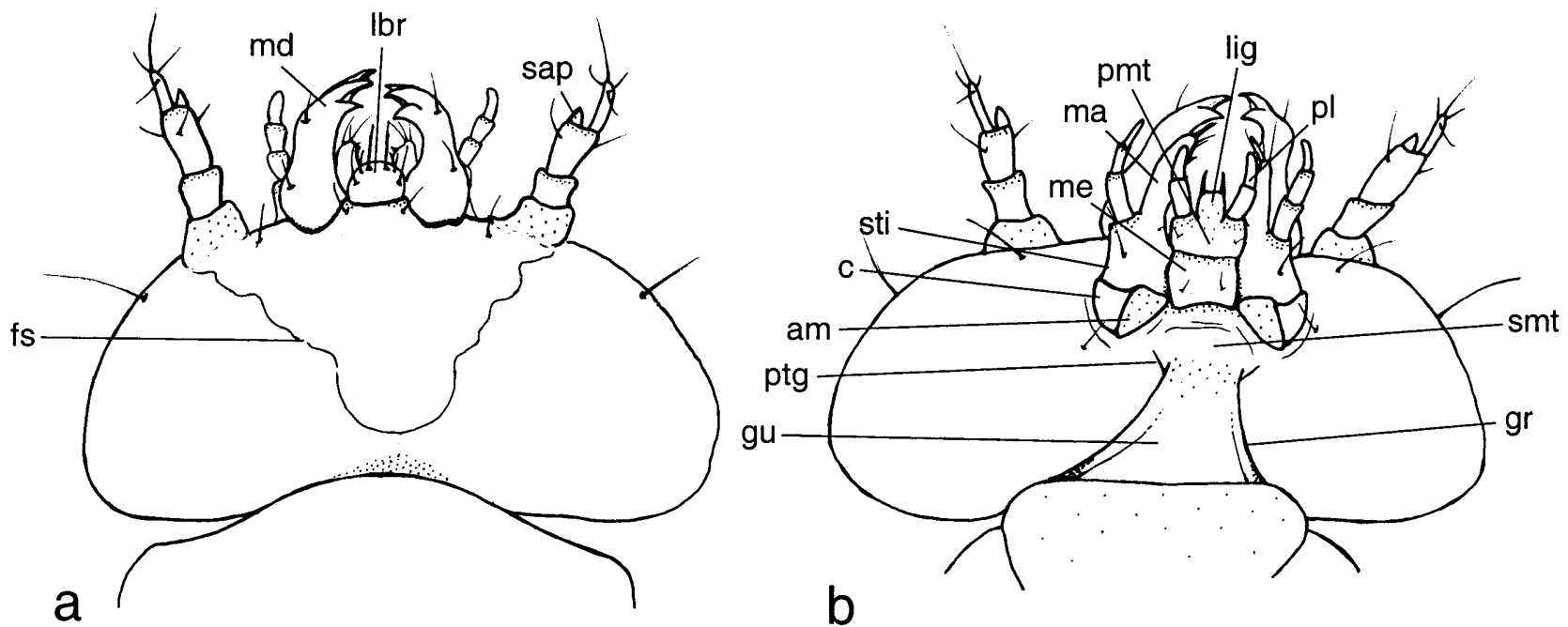

Fig. 1. Prostomis mandibularis, head. a - dorsal view; $\mathrm{b}$ - ventral view. am - pad-like articulatory membrane; $\mathrm{c}-\mathrm{cardo}$; fs frontal suture; gr - gular ridge; gu - gula; lbr - labrum; lig - ligula; ma - mala; md - mandible; me - mentum; pl - palpus labialis; pmt - praementum; ptg - posterior tentorial grooves; sap - sensorial appendage; smt - submentum; sti - stipes.

bach, Baden Württemberg, Germany. Larvae were collected from infested trees and fixed in Bouin. Pupae were obtained from larvae that were reared in the laboratory in petri dishes filled with decaying wood from the infested tree.

Larvae and pupae were dehydrated in ethanol, critical-point dried, and sputter-coated with gold-palladium for SEM (Cambridge Stereoscan $250 \mathrm{Mk} 2$; Institut für Biologie III, Universität Tübingen; FEO ESEM XL30, Biologisch-Pharmazeutische Fakultät, FSU Jena).

For microtome sectioning, selected larvae were embedded in Historesin (Leica Historesin) or in Technovit (Kulzer Technovit 7100). Sections were cut at $3 \mu \mathrm{m}$ with a rotation microtome (Supercut, Reichert-Jung 2050). Glass knives were used for specimens embedded in Historesin and Kulzer Histoknives for specimens in Technovit. All sections were stained with methylene-blue and basic fuchsine. Drawings and dissections of larvae were carried out with a stereo microscope and camera lucida and drawings of serial sections with a microscope with ocular grid. Pictures of the serial sections were taken with a Zeiss Axioplan Mikroskop and a MC 100 camera.

The nomenclature of head muscles was adopted from von Kéler (1963).

\section{List of additional material studied (preserved in ethanol unless otherwise noted).}

Tenebrionoidea, Melandryidae: Orchesia micans (Panzer, 1794) (Dubosq Brazil); Pyrochroidae: Pyrochroa Geoffroy, 1762 spp. $($ FAE $=$ formaldehyde + ethanol + acetic acid $)$; Pythidae: Pytho Latreille, 1796 spp. (Kahle's fluid); Colydiidae: Bitoma crenata (Fabricius, 1775) (FAE)

Cucujoidea, Sphinididae: Sphindus americanus LeConte, 1866; Silvanidae: Oryzaephilus Ganglbauer, 1988 sp. (FAE), Silvanus Latreille, 1807 sp. (FAE); Nitidulidae: Glischrochilus Reitter, $1873 \mathrm{sp.}$

Cleroidea, Phycosecidae: Phycosecis Pascoe, 1875 sp.

\section{MORPHOLOGICAL RESULTS}

\section{Larva}

\section{General appearance}

The larvae are strongly flattened dorsoventrally (Figs $2 \mathrm{a}, \mathrm{b})$. The total length of final instars varies between 7,5 and $9 \mathrm{~mm}(\mathrm{n}=20)$. The greatest width is at the level of the abdominal segment $\mathrm{V}$. The larvae taper slightly towards the head and more distinctly posteriorly. The mouthparts are the darkest parts of the body and strongly sclerotized. The cuticle of the head capsule and the body segments is of cream-white colour, smooth, shiny and semi-transparent. The mid-gut is filled with woodparticles and clearly visible externally. The setation is sparse.

\section{Head capsule}

The head is strongly flattened, transverse, about twice as wide as long, and distinctly asymmetric, with the right side being more expanded compared to the left. It is distinctly prognathous with the dorsal and ventral side nearly parallel. Its longitudinal axis is continuous with the longitudinal axis of the body and the mouthparts are in a horizontal position. Few setae are present on the head capsule (distribution see Figs 1a, b; 2a-b). The labrum is moveably connected with the anterior clypeal margin by an internal membranous fold. The frontoclypeal suture is absent. The frontal suture (= frontal arms) is lyriform, forming a $U$ posteriorly. The anterior part is indistinct. The coronal suture (= epicranial stem) is very indistinct and short. A median or Y-shaped endocarina is absent. Hypostomal rods and ventral epicranial ridges are also missing. The maxillary grooves are moderately deep. The fissure-shaped posterior tentorial grooves enclose the anterior part of the long and broad, posteriorly diverging gula, which is laterally delimited by very distinct gular sutures and corresponding internal ridges (Fig. 1b).

\section{Internal skeletal structures}

The gula is laterally bordered by the internal gular ridges and anteriorly by the bases of the well developed posterior arms. The dorsal arms are unsclerotized and flat. The broad, apodeme-like apical part is attached to the head capsule (Figs 7c-d; 8a). The tentorial bridge is 

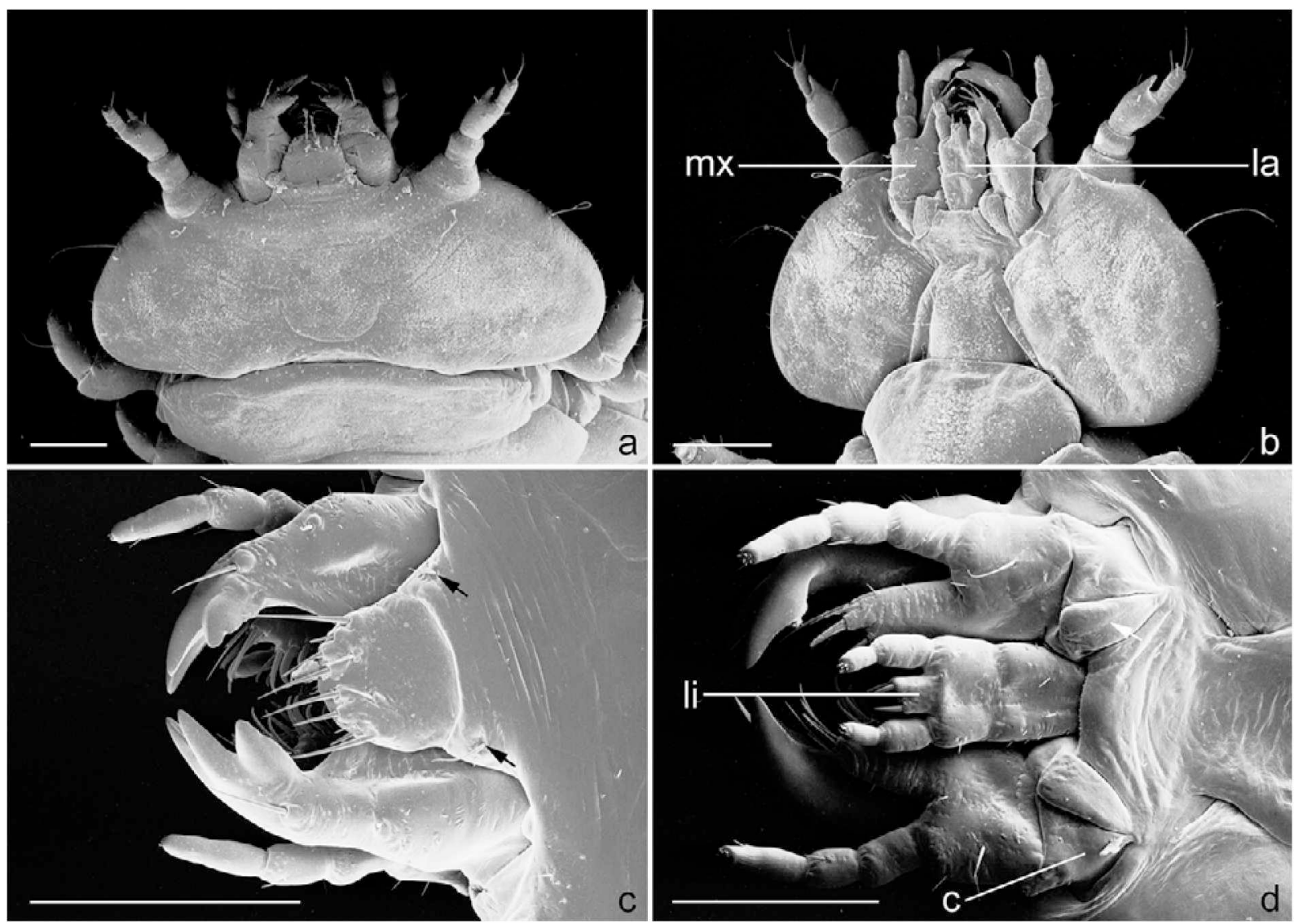

Fig. 2. Head, SEM micrographs. a - dorsal view; $b$ - ventral view; $c, d-$ anterior head region, appendages; $c$ - dorsal view, small sensilla close to clypeal margin (marked by arrow); $d$ - ventral view, pad-like articulatory area of maxillae (marked by arrow). Scale bar a-d $=200 \mu \mathrm{m}$. c - cardo; la - labium; li - ligula; $\mathrm{mx}$ - maxilla.

broadened and plate-like (Fig. 8a). The anterior arms are absent.

\section{Labrum}

The labrum is small and rounded anteriorly. A series of ten symmetrically arranged setae is present along the anterior margin (Figs 2a, 2c). A pair of small sensilla inserts close to the clypeal margin (Figs 2a, 2c). All microstructures on the ventral side (= epipharynx) are asymmetric. An asymmetric field of microtrichia is present along the median line (Fig. 3a). The median line is interrupted in the posterior area by strong transverse folds and a group of stronger microtrichia and paired fields with rhomboid scales are present posterior to these structures (Figs 3a-b). Each of the scales is laterally set with pectinate hairs (Fig. 3b).

Musculature: M. labroepipharyngalis (M. 7) and M. frontoepipharyngalis (M. 9) are absent.

\section{Antennae}

The antennae are 3-segmented. They insert on a strongly prominent, semimembranous articulatory area (Figs 1a, 2a). Antennomere I is slightly longer than broad. Antennomere II is almost twice as long as I. Antennomere III is slender and slightly shorter than II (Figs 2a, 5a). The sensorial appendage is inserted on the mesal apex of antennomere II, conical and half as long as antennomere
III. A whirl of five setae is present proximal to its insertion. A long seta and three shorter setae are present on the apex of antennomere III (Fig. 5a) and a round sensorial field on the mesal side at the level of the tip of the sensorial appendage (Figs 5b-c).

Musculature: M. tentorioscapalis anterior, posterior and medialis (M. 1, 2 and 4) originate dorsally on the head capsule, lateral to the attachment of the dorsal tentorial arms; they insert anteriorly, posteriorly and dorsally on the base of antennomere I (Figs 7a-b).

\section{Mandibles}

The mandibles are elongate and asymmetric, with two long setae on the lateral side (Figs 2c, 3f). The left mandible is slightly longer. The left mola is larger and bears a distinctly projecting molar tooth (Figs $3 \mathrm{~d}, 3 \mathrm{f}$ ) and a ventral field with minute cuticular spines (Figs 3d, 4c). The right mola is posteriorly prolonged, thus forming a posteriorly directed tooth-like process (Fig. 3c, 6: pmth). The surface of both molae is transversely ridged (Fig. 3c) and a dorsal field with a pectinate microsculpture is present on the dorsal side (Figs 3e-f). The tridentate mandibular apices are strongly sclerotized and darker than the remaining parts. The left apex lies above the right apex when the mandibles are in the flexed position (Figs 2b-c).

Musculature: M. craniomandibularis internus (M. 11), the largest muscle of the head, originates on extensive 

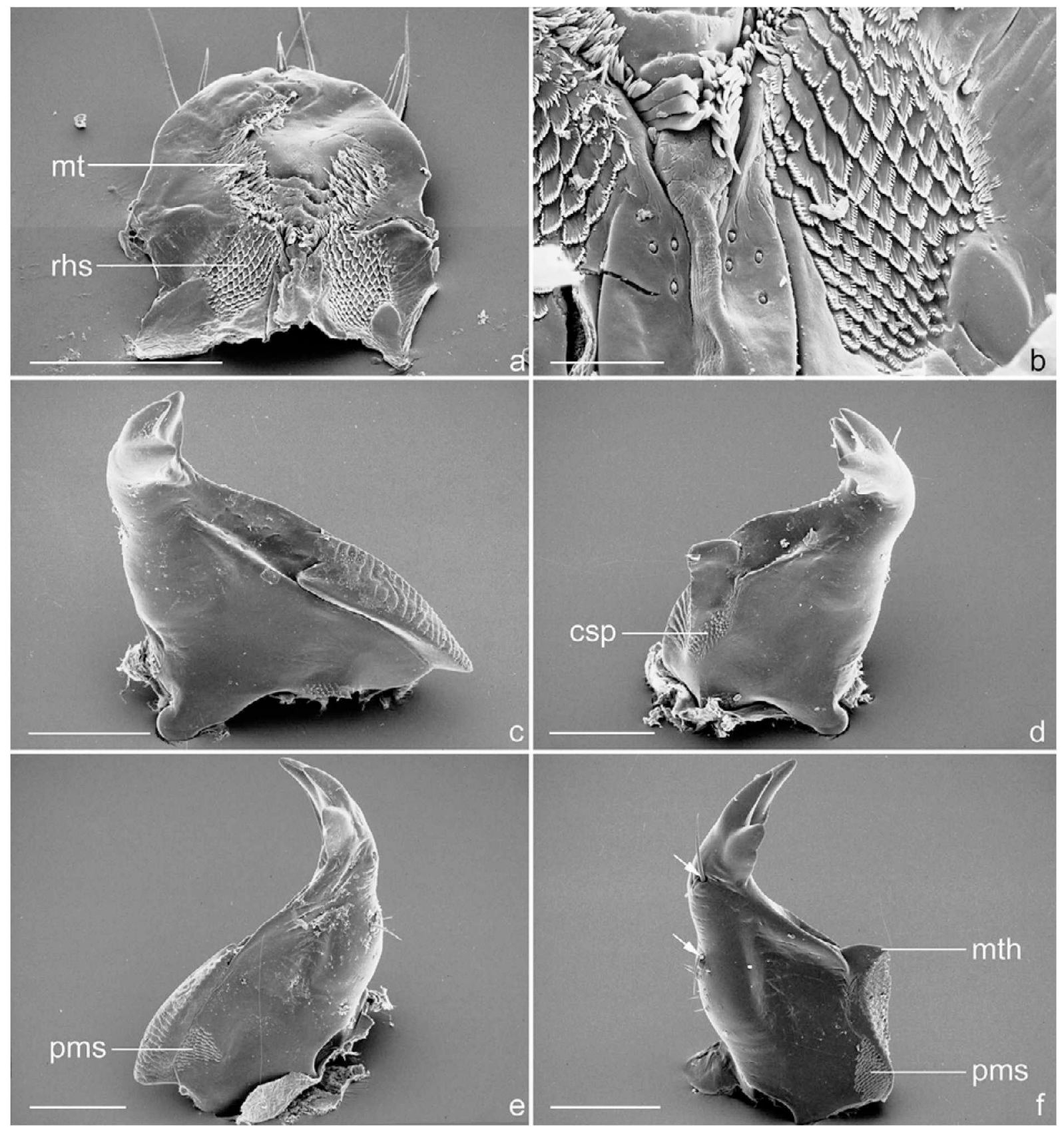

Fig. 3. Head appendages, SEM micrographs. a - labrum, ventral view; $b$ - inner labral surface (epipharynx) with rhomboid scales; $\mathrm{c}$ - right mandible, ventral view; $\mathrm{d}$ - left mandible, ventral view; e - right mandible, dorsal view; $\mathrm{f}$ - left mandible, dorsal view, arrows point to long setae. Scale bar a, $c-f=100 \mu \mathrm{m} ; \mathrm{b}=20 \mu \mathrm{m}$. csp - cuticular spines; $\mathrm{mt}$ - microtrichia, mth - molar tooth; pms pectinate microsculpture; rhs - rhomboid scales.

dorsolateral, lateral and ventrolateral areas of the head capsule. The multiple bundles insert on a large tendon, which is mesally attached to the mandibular base (Fig. 7a). M. craniomandibularis externus (M. 12) is distinctly smaller and originates ventrolaterally from the head capsule, close to the foramen occipitale; it inserts on a slender tendon, which is laterally attached to the mandibular base (Fig. 7a).

\section{Maxillae}

The articulatory area of the maxillae is covered by a shiny, semimembranous pad-like structure. The cardo is undivided, roughly triangular, with a very slightly rounded lateral margin (Fig. 2d). The stipes is broad and fairly short and fused with the mala. The dorsal stipital surface is partly covered with microtrichia and pectinate scale-like structures (Figs 4d-e). The mala is rounded apically and a notch is absent. It bears a group of 6 setae of different length and thickness (Figs 4d-e). A short subapical part of the mesal margin is free of hairs or spines. It is proximally bordered by a group of long, apically curved spines, which insert on distinct sockets. Two rows of shorter curved spines are present proximomesally (Fig. 4d). Bundles of longer microtrichia are arranged in rows on the base of the palp (Fig. 4e). The palp is 


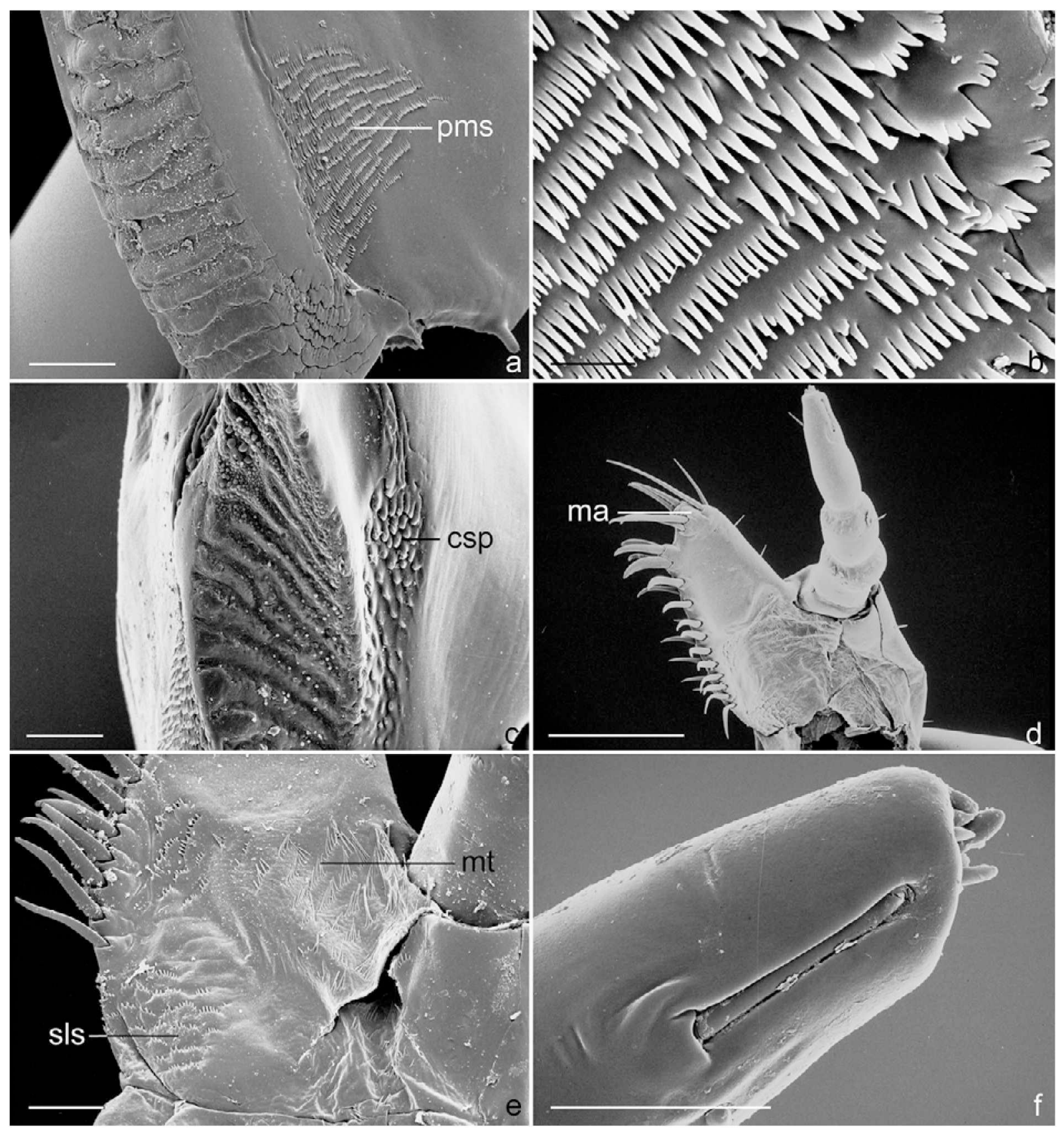

Fig. 4. Head appendages, SEM micrographs. $a-$ molar surface of right mandible; $b$ - pectinate microsculpture on right mandible; $\mathrm{c}$ - left mandible, mola, mesal view; $\mathrm{d}$ - maxilla, dorsal view: mala with six setae; $\mathrm{e}$ - maxilla, dorsal view; $\mathrm{f}$ - apical maxillary palpomere with digitiform sensillum. Scale bar a, c, e-f $=20 \mu \mathrm{m}, \mathrm{b}=4 \mu \mathrm{m}, \mathrm{d}=100 \mu \mathrm{m}$. csp - cuticular spines; ma - mala; mt - microtrichia; pms - pectinate microsculpture; sls - scale-like structure.

3-segmented. The proximal palpomeres are shorter and broader, the distal palpomere is narrower, tapering towards the apex and nearly twice as long as the proximal segment (Figs 2d, 4d). Distally, it bears a long, lateral digitiform sensillum (Fig. 4f).

Musculature: M. craniocardinalis (M. 15) is absent; M. tentoriocardinalis (M. 17) originates from the tentorial bridge and is divided into 2 bundles; M. 17a inserts medially on the base of the cardo, M. 17b laterally, on the ventral cardinal wall; M. tentoriostipitalis (M. 18) originates from the tentorial bridge close to M. 17 and inserts on the mesal edge of the stipes (Figs 7a-8a); M. craniolacinialis
(M. 19) originates ventrolaterally on the posterior margin of the head capsule and inserts on the mala (Figs 7a-8a); M. stipitolacinialis (M. 20), M. stipitogalealis (M. 21), M. stipitopalpalis externus (M. 22) and M. stipitopalpalis internus (M. 23) are absent.

\section{Labium}

The labium is narrow, about $1.5 \times$ longer than wide, and free to the base of the mentum (Figs 2b-d). The submentum is roughly trapezoid. It is posteriorly adjacent to the gula and separated from it by a transverse fold. Anteriorly it is inserted between the maxillary grooves. The mentum is narrow and converging posteriorly. The pre- 

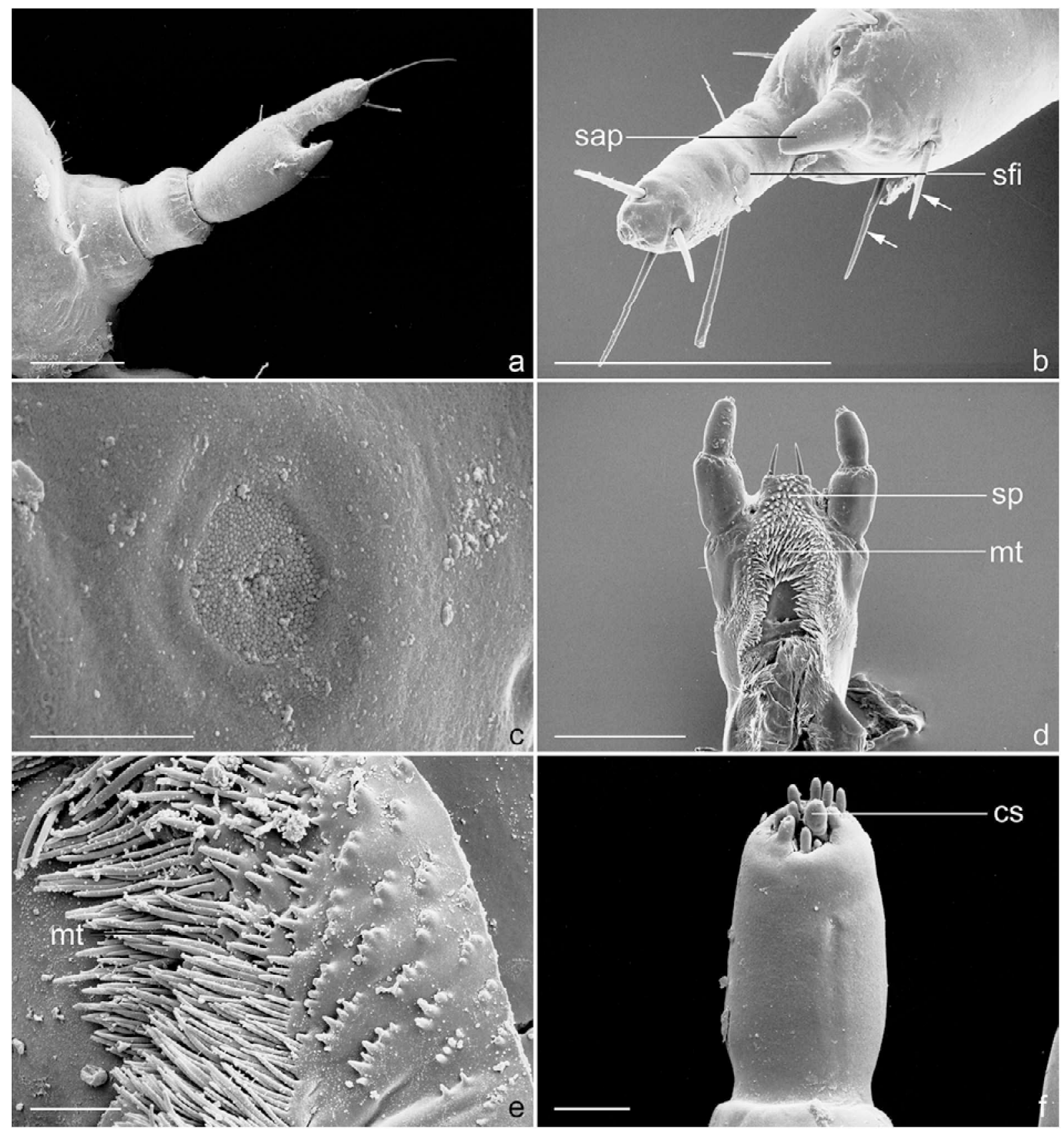

Fig. 5. Head appendages, SEM micrographs. $a$ - antenna, ventral view; $b$ - distal antennomere, arrows indicate two out of five setae of apical whirl on antennomere 2; $\mathrm{c}$ - sensorial field of distal antennomere; $\mathrm{d}$ - prementum and hypopharynx, dorsal view; $\mathrm{e}-$ premental surface; $\mathrm{f}$ - apical labial palpomere. Scale bar a-b, $d=100 \mu \mathrm{m}, \mathrm{c}=4 \mu \mathrm{m}$, e-f $=10 \mu \mathrm{m}$. cs - conical sensillum; mt - microtrichia; sap - sensorial appendage; sfi - sensorial field; sp - spines.

mentum is well-developed, roughly triangular and about as broad as the anterior margin of the mentum. A distinct ligula is present. It bears a pair of strong setae on its anterior margin (Fig. 2d). The palp is 2-segmented (Fig. 5d). The distal palpomere is distinctly narrower than the proximal segment. A conical sensillum is present on its apex. It is surrounded by a ring of smaller sensilla (Fig. 5f). A digitiform sensillum is missing. On the dorsal side, the ligula is covered with short strong spines (Figs 5d-e).

Musculature: M. submentopraementalis (M. 28) originates posteromedially on the submentum and inserts on the posterior margin of the prementum (Figs 6, 7b); M. tentoriopraementalis (M. 29) inferior, M. tentoriopraementalis superior (M. 30) and M. praementopalpalis (M. 34) are absent.

\section{Epipharynx}

The anterior part, i.e. the ventral side of the labrum is described above. The posterior epipharynx is laterally fused with the posterior hypopharynx, thus forming a closed prepharyngeal tube. Tormae, i.e. distinct lateral sclerotisations of the epipharynx are not developed (Fig. $7 \mathrm{a}, \mathrm{b})$. 


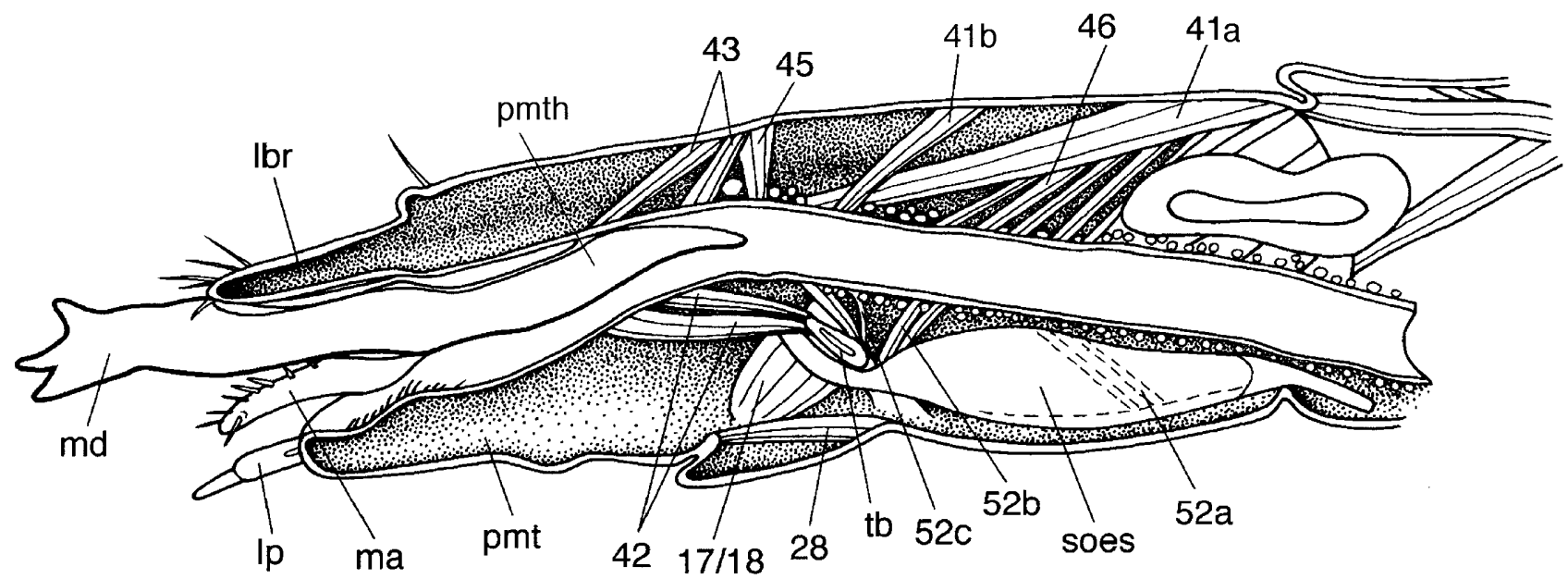

Fig. 6. Head, sagittal section. lbr - labrum; lp-pl - palpus labialis; ma - mala; md - mandible; ph - pharynx; pmt - praementum; pmth - posterior molar tooth; soes - suboesophageal ganglion; $\mathrm{tb}$ - tentorial bridge; 17 - M. tentoriocardinalis; 18 - M. tentoriostipitalis; 28 - M. submentopraementalis; 41 - M. frontohypopharyngalis; 42 - M. tentoriohypopharyngalis; 43 - M. clypeopalatalis; 45, $46-\mathrm{M}$. frontobuccalis anterior, posterior; $52-\mathrm{M}$. tentoriopharyngalis.

Musculature: M. clypeopalatalis (M. 43), is composed of 2 subcomponents, 43 a originates immediately anterior to M. frontobuccalis anterior (M. 45) and inserts on the posteriormost epipharynx. M. 43b originates immediately anterior to M. 43a and inserts on the epipharynx above the molar areas of the mandibles (Figs 6, 7b, 8a).

\section{Hypopharynx}

The anterior part is not clearly separated from the dorsal premental surface. Posterior to the ligula, a roughly symmetrical semicircular field of microtrichiae is present. Posteriorly it encloses a median smooth concavity (Fig. 5d). A strong sclerotization is present at the level of the mandibular mola (Fig. 7a). The posterior hypopharynx is laterally fused with the posterior epipharynx (see above).

Musculature: M. frontohypopharyngalis (M. 41) is a large and bipartite muscle; M. 41a originates from the posteriormost frontal region; it inserts laterally on the hind margin of the prepharynx with a strong tendon (Figs $7 \mathrm{c}, 8 \mathrm{~d}) ;$ M. $41 \mathrm{~b}$ originates from the anterior part of the frons and inserts together with M 41a. M. tentoriohypopharyngalis (M. 42) originates medially from the platelike tentorial bridge. It inserts ventromedially on the posterior hypopharynx (Figs 6, 7c-d).

\section{Pharynx}

The pharynx is wide, with distinct folds for attachment of dorsal and ventral dilatators. The ring musculature is modestly developed (Fig. 7a).

Musculature: M. frontobuccalis anterior (M. 45), originates from the anterior frons and inserts dorsally on the anatomical mouth (Figs 6, 7c); M. frontobuccalis posterior (M. 46) originates as a very flat bundle lateral to M. frontohypopharyngalis (M. 41) and inserts dorsally on the precerebral part of the pharynx. M. tentoriobuccalis (M. 50) and M. verticopharyngalis (M. 51) are absent; M. tentoriopharyngalis (M. 52), is composed of 3 subcomponents; M. 52a originates from the gular ridge and inserts ventrolaterally on the posterior pharynx; M. 52b origi- nates on the basal part of the posterior tentorial arms and inserts ventrolaterally on the anterior pharynx; the strongly developed M. 52c originates from the tentorial bridge and inserts ventrally on the anterior pharynx, immediately anterior to M. 52b (Figs 6, 8c-d).

\section{Cerebrum}

The hemispheres of the cerebrum reach posteriorly into the anterior prothorax. They are tapering towards their anterior apex. The slender tritocerebral parts are anteriorly oriented, connected with each other by the tritocerebral commissure, and with the suboesophageal ganglion by the circumoesophageal connective. The protocerebral commissure lies approximately at the level of the posterior margin of the suboesophageal ganglion (Fig. 6). In a larva fixed shortly before the pupal moult, the cerebrum was completely shifted to the right side of the head.

\section{Glands}

Paired tubular glands enter the head capsule on both sides of the suboesophageal ganglion. The precise location of the anterior opening could not be identified. The tubes are not traceable on the available microtome sections anterior to the anatomical mouth (Fig. 8c).

\section{Prothorax}

The prothorax is narrower than the head and the abdomen. A median suture is not recognisable on the protergum. The prosternum is divided into two unpaired and two paired, distinctly separated sections (Fig. 9b): A large, roughly triangular anteromedian plate (presternum), paired medially adjacent oblique intercoxal plates (basisternum), a trapezoid posteromedian plate (sternellum) and a pair of bulging, posterolateral sclerites. The legs are 5-segmented (Young, 1991), fairly short, and broadly separated (Fig. 9c). The coxae are indistinct. The trochanters are well developed and ring-like. The femur is the longest segment. Several setae are inserted on its ventral side. The tibiotarsus is slightly more than half as long 


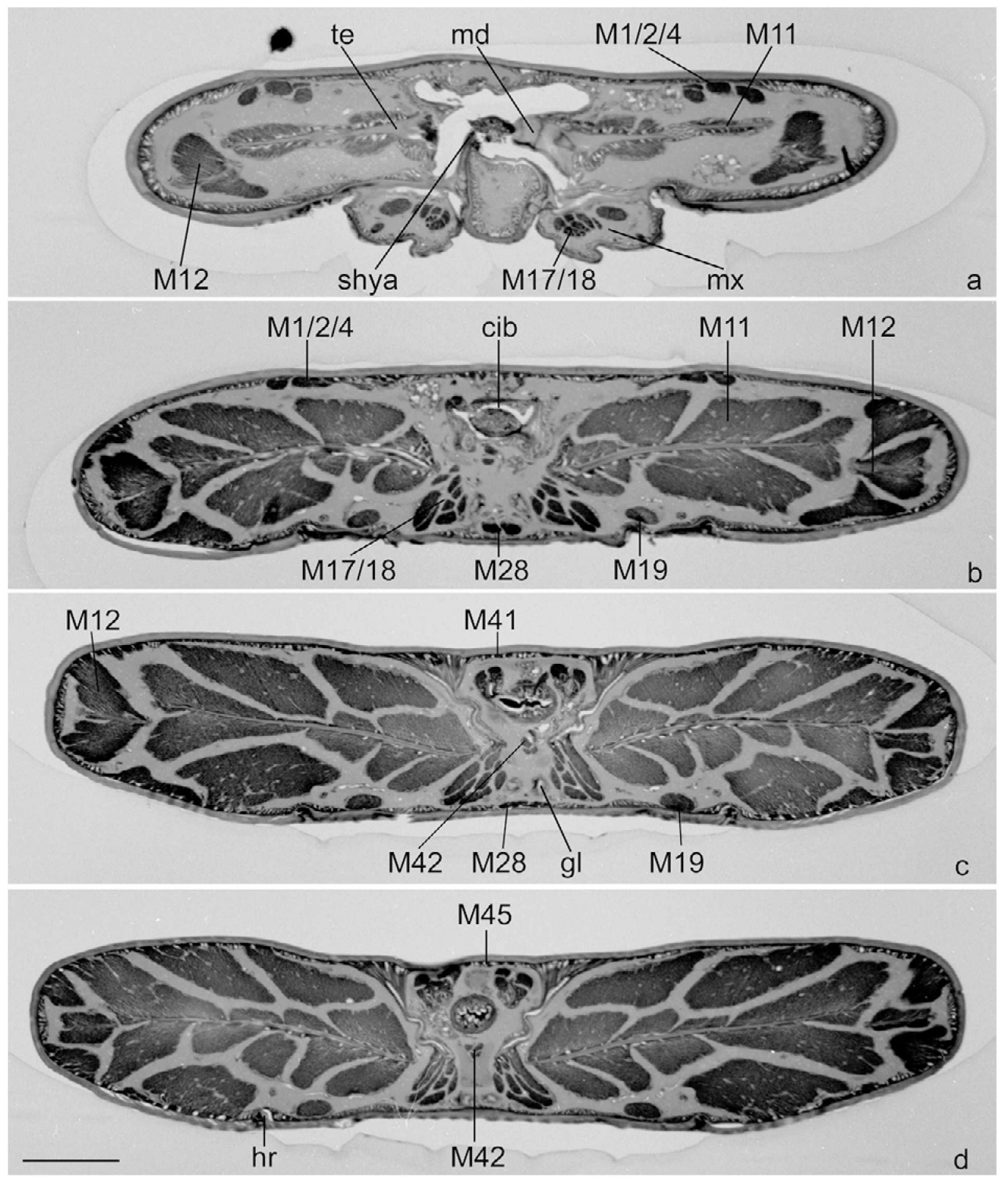

Fig. 7. Internal head structures, cross sections. a - hypopharyngeal region; $b-$ anterior prepharyngeal region; $c$ - posterior prepharyngeal region; $\mathrm{d}$ - anterior pharyngeal region. Scale bar a-d = $100 \mu \mathrm{m}$. cib - cibarium; gl - gland; hr - hypostomal ridge; md mandible; $\mathrm{mx}$ - maxilla; shya - sclerotised hypopharyngeal area tendon; M1, 2, 4-M. tentorioscapalis anterior, posterior, medialis; M 11, 12 - M. craniomandibularis internus, externus; 17 - M. tentoriocardinalis; 18 - M. tentoriostipitalis; 19 - M. craniolacinialis; 28 - M. submentopraementalis; 41 - M. frontohypopharyngalis; 42 - M. tentoriohypopharyngalis; 43 - M. clypeopalatalis; 45 - M. frontobuccalis anterior.

as the femur and narrower. It bears several spine-like setae (Fig. 9d) dorsally and distally, and at its distal end a single long seta above the claw (Fig. 9c). The claws show a characteristic surface structure of longitudinal riffles (Fig. 9d).

\section{Mesothorax}

An indistinct suture divides the tergum medially and a small but distinct circular pit is present on both sides of it (Fig. 9a). The sternal region is composed of a flat and broad undivided anterior part with distinct origins of the sternal apophyses (basisternum + sternellum), a slightly 


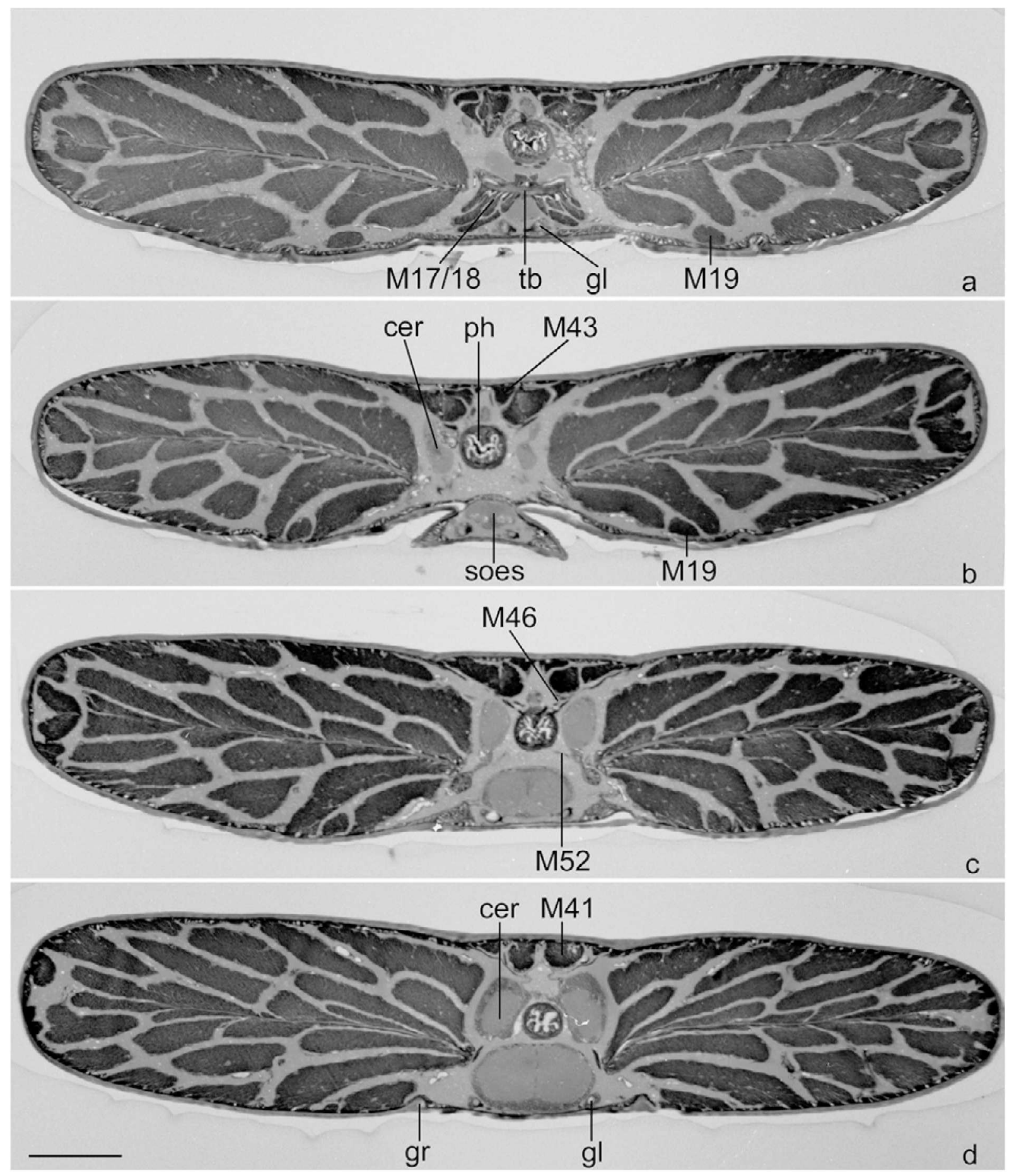

Fig. 8. Internal head structures, cross sections. $\mathrm{a}$ - tentorial bridge region; $\mathrm{b}-$ anteriormost cerebral region; $\mathrm{c}-$ attachment area of M. 46; d - posterior cerebral region. Scale bar a-d = $100 \mu \mathrm{m}$. cer - cerebrum; gl - gland; gr - gular ridge; ph - pharynx; soes suboesophageal ganglion; th - tentorial bridge; 17 - M. tentoriocardinalis; 18 - M. tentoriostipitalis; 19 - M. craniolacinialis; 41 M. frontohypopharyngalis; $43-$ M. clypeopalatalis; $46-\mathrm{M}$. frontobuccalis anterior; $52-\mathrm{M}$. tentoriopharyngalis.

bulging, transverse posterior area, and bulging posterolateral sclerites (Fig. 9b). The spiracle is located on a very prominent, cone-shaped elevation between the pro- and mesothorax (Figs 9a-b, 10a). The middle legs are very similar to the fore legs.

\section{Metathorax}

The metathorax is similar to the mesothorax. The transverse posterior sternal part is shorter and spiracles are absent.

\section{Abdominal segments I-VIII}

The abdominal segments I-VIII are unpigmented and strongly flattened like the head and thorax. They are 

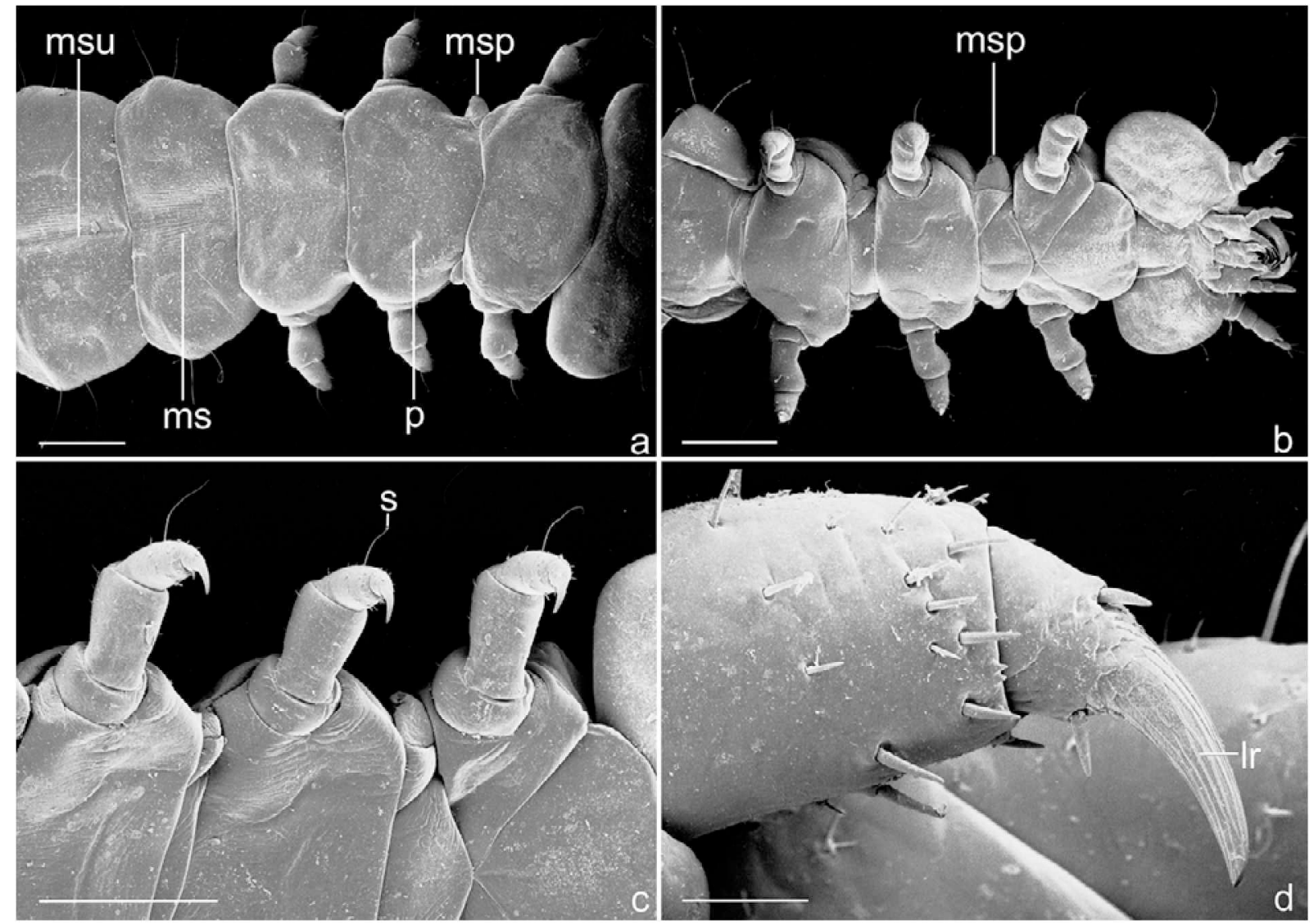

Fig. 9. Thorax, SEM micrographs. a - dorsal view; $b$ - ventrolateral view; $c$ - ventral view legs; note: long seta on tibiotarsi; $d-$ tibiotarsus of fore leg. Scale bar a-c $=400 \mu \mathrm{m}, \mathrm{d}=40 \mu \mathrm{m}$. $\mathrm{lr}$ - longitudinal riffles; ms - microsculpture; msp - mesothoracic spiracle; msu - median suture; $\mathrm{s}$ - seta.

about twice as wide as long. The width is increasing towards segment $\mathrm{V}$ and decreasing posteriorly. The tergites are divided by an indistinct median suture. A fine, undulating longitudinal microsculpture is present on the sternites and tergites (Figs 9a, 10c). Ampullae and asperities are absent. Short paramedian and long lateral longitudinal furrows are present on the sternites. The spiracles lie on a smooth lateral area approximately in the middle of the segments. This pleural area is dorsally delimited by a longitudinal ridge and ventrally by a bulge, which extends from the anteroventral part of the segment to the dorsal side (Figs 10b-c). Short, posteriorly directed spines are present anterior and posterior to the spiracles (Fig. $10 \mathrm{~b}$ ). A group of one short and four longer setae is present laterally around the spiracular area (Figs 10b-c).

\section{Abdominal segments IX and $X$}

The abdominal segment IX is approximately half as wide as segment V. The apices of the well-developed, immovable urogomphi are strongly sclerotized (Figs 10d-f). Tergum IX extends to the ventral side and forms a plate together with the urogomphi, which articulates with segment VIII. The lateral sides of the segment and the urogomphi are covered with tubercles with a short bristle inserted on their apex (Pollock, 1991) (Figs 10e-f). A long seta inserts in the middle of the lateral side (Fig. 10e). Sternite IX is partly enclosed by sternite VIII. Apically, it carries a row of 14 spines (Fig. 10e). Segment $X$ is small, ventrally directed and not visible from the dorsal side (Fig. 10e). The anus opens between segment $X$ and sternite IX (Fig. 10f).

\section{Spiracles}

All abdominal spiracles are annular-biforous (Young, 1991) (Figs 10b-c).

\section{Pupa}

The pupa is adecticous with free appendages. The cuticle is of a pure white colour. The body is dorsoventrally flattened (Fig. 11a), moderately broad anteriorly and tapering posteriorly. It is $4.1 \mathrm{~mm}(\mathrm{n}=3)$ long. The head is ventrally inflected and not visible in dorsal view. It is as broad as the pronotum and approximately 3 times broader than long. Labrum and maxillae are enclosed in a common sheath (Fig. 11a), which is elongate, nearly reaching the mandibular apex, and apically concave. The mandibles are strongly developed. They cover the fore legs almost completely together with the labro-maxillary sheath. The antennae are placed on the femorae of the fore and middle legs. The apical part rests on the ventral side. The antennomeres are expanded towards the antennal apex. Short strong spines are developed on antennomeres 7-11 (Fig. 11b). Paired setae of approximately equal length are present on the head capsule, one laterally and two at the base of the antenna, one of them with the same orientation as the antenna, the other one 

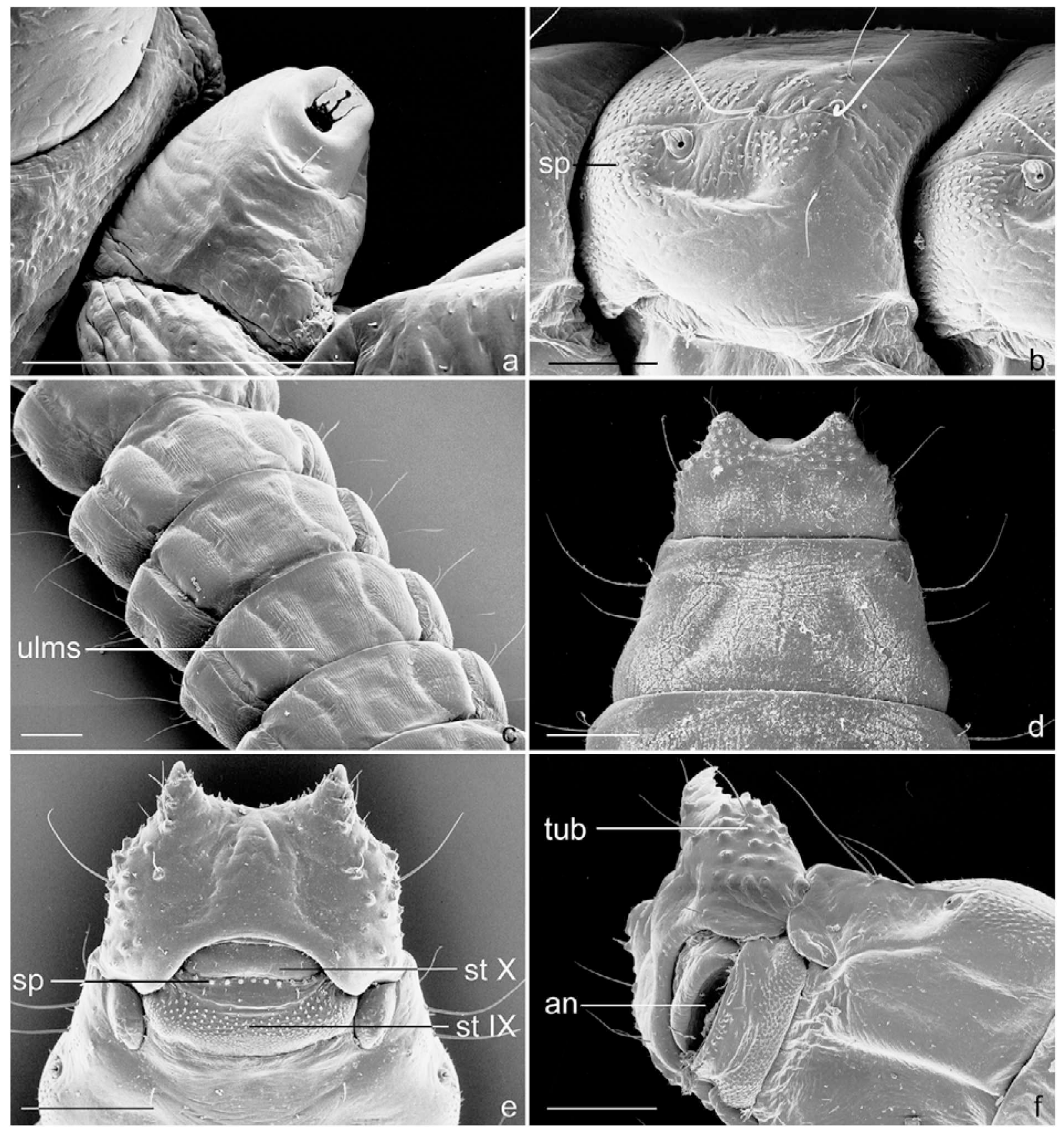

Fig. 10. Spiracles, abdomen, SEM micrographs. a - mesothoracic spiracle; $b$ - biforous spiracle of $2^{\text {nd }}$ abdominal segment; $\mathrm{c}-$ segments III-V, ventral view; d - segments VIII-IX, dorsal view; e - segments VIII-X, ventral view; f - segments VIII-X, ventrolateral view. Scale bar $\mathrm{a}-\mathrm{b}=100 \mu \mathrm{m}, \mathrm{c}-\mathrm{f}=200 \mu \mathrm{m}$. an - anus; $\mathrm{sp}-$ spines; st - sternite; tub - tubercles; ulms - undulating longitudinal microsculpture.

directed towards the median region of the head. Two setae are symmetrically placed on a transverse fold of the central head region. A shorter seta occurs on the base of the labro-maxillary sheath. The pronotum is nearly rectangular and divided by a median suture (Fig. 11c). Two pairs of symmetrically placed tubercles, each bearing a long seta, are present at the anterior margin (tubercles: see Pollock, 1991) (Fig. 11c). The lateral pronotal margin forms a semicircular bulge, with two pairs of tubercles arranged in a similar pattern, with anteriorly directed setae (Fig. 11c). A very short seta is situated lateral to the median suture at posterior margin of the pronotum. Three short setae are arranged symmetrically on a transverse line on the central part of the pronotum. The metathorax is longer than the mesothorax. A seta is present lateral to the indistinct median line (Fig. 11d). The elytral and hind wing sheaths are inflected onto the ventral side. They reach the caudal end of abdominal segment $\mathrm{V}$ and cover the hind legs, except for the femuro-tibial joint and the tarsal apex (Fig. 11a). Two medium length setae are present at each joint (Fig. 11a). The abdomen is composed of nine distinct segments. It is slightly inclined ventrally (also in live pupae). The posteromedian and anteromedian edges of several tergites, especially of tergites II and III, 

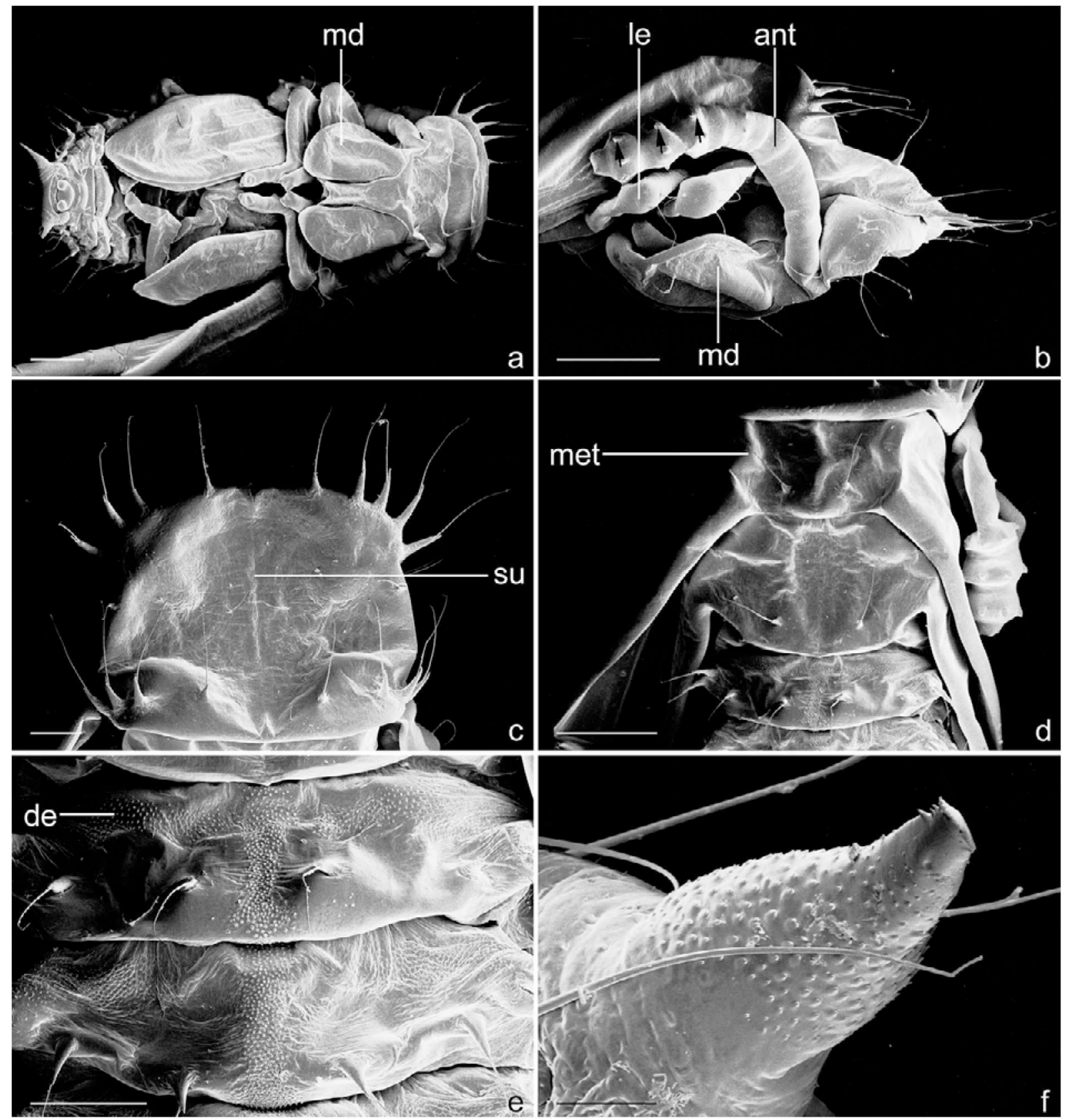

Fig. 11. Pupa, SEM micrographs. a - ventral view, with labrum and maxillae in common sheath; $\mathrm{b}$ - lateral view; antenna with short strong spines (marked by arrows); $\mathrm{c}$ - pronotum; $\mathrm{d}$ - metathorax and abdominal segments I and II, dorsal view; e - tergites I and II, with "gin traps"; f - urogomphus. Scale bar a-d $=400 \mu \mathrm{m}$, e $=200 \mu \mathrm{m}, \mathrm{f}=40 \mu \mathrm{m}$. ant - antenna; de - denticles; le - leg; md - mandible; met - metathorax; su - suture.

are equipped with short spines. A median row of numerous small denticles is present on tergites I-VII (Fig. 11e) (limited to the anterior half on tergite VII). Similar denticles are present at the anterior margin of these segments (Fig. 11e). They are completely absent on tergites VIII and IX. The urogomphi are elongate and equipped with denticles. The apex is sclerotized and the lateral edge is serrate (Fig. 11f). The distribution of dorsal, lateral and ventral setae is similar in all abdominal segments (Figs 11d-e).

The sex of pupae can be easily distinguished by the strongly elongated mandibles in males.

\section{FUNCTION OF MOUTHPARTS AND MECHANISMS OF INGESTION}

Wood material is mechanically processed between the transversely ridged molar surfaces and between the ventral surface of the left mola and a complementary sclerotized hypopharyngeal area on the left side (Fig. 7a), respectively. The posterior molar part of the right mandible reaches deeply into the prepharynx and pushes material towards the anatomical mouth (Fig. 6: pmth). The pectinate microstructures on the dorsal side of the mandibles interact with the rhomboid scales of the anterior epipharynx (Figs 3a-b, 4a, b), and the surface modifi- 
cations on the ventral side of the mandibles with the semicircular, pectinate scales of the dorsal stipital surface (Figs 4c-e). The dorso- and ventromesal spines of the mala remove material from the epi- and hypopharyngeal fields of microtrichia (Figs 4d, 5d-e). The food mass is processed and transported towards the pharynx by the coordinated, alternating movements of the mandibles and maxillae.

The food transport in the prepharynx is supported by synergistic contractions of M. clypeopalatalis (M. 43a, b) and M. tentoriohypopharyngalis (M. 42). Both extend the prepharynx anterior to the anatomical mouth. The pharyngeal pumping activity is achieved by alternating contractions of dorsal and ventral dilators and the ring musculature. M. frontobuccalis anterior (M. 45) functions as a dilator of the anatomical mouth, together with the anterior bundle of M. tentoriopharyngalis (M. 52c). The two subcomponents of M. frontohypopharyngalis (M. 41) extend the precerebral pharynx together with the anterior bundles of M. tentoriopharyngalis (M. 52c). M. frontobuccalis (M. 46) dilates the posterior precerebral pharynx together with the posterior bundles of M. tentoriopharyngalis (M. $52 \mathrm{a}$ and $52 \mathrm{~b})$.

\section{LOCOMOTION}

Larvae of Prostomis mandibularis were always encountered inside the decaying wood and never under the bark. The strongly flattened, prognathous head and the strongly flattened body are adaptations to the locomotion in the extremely narrow interspaces between wood fibres. It is plausible to assume that the apical regions of the elongate mandibles force the way into these tight crevices, supported by anteriorly directed forces created by the short legs with the strong claws in an alternating sequence. The urogomphi are rarely used as support during locomotion. The abdomen appears to be moved forward by coordinated antagonistic action of contracting abdominal muscles and forces created by an increased hemolymph pressure in the segments. This results in an earthwormlike pattern of movements of the abdomen.

\section{PUPAL PROTECTING DEVICES}

It is likely that the posteromedian and anteromedian spines of the abdominal tergites II and III function as pupal protective devices ("gin traps"; Hinton, 1946).

\section{DISCUSSION}

The monophyly of Prostomidae is well established. The distinct asymmetry of the larval head capsule, the presence of a sensorial field on antennomere III, the posteriorly directed process of the right mola, and the elongated and broadened mandibles of pupae and adults are very unusual features and almost certainly autapomorphies of the family. The very unusual, elongate labro-maxillary sheath of the pupa is likely another autapomorphy, but very little detailed information on pupal characters of tenebrionoid taxa is presently available (e.g., Costa et al., 1995, 1998; Pollock et al., 2000). The complete absence of stemmata is also a derived feature, but loss of stem- mata occurs rather frequently, especially in larvae with subcortical or wood-boring habits (e.g., Boridae partim, Trictenotomatidae, Pediliae partim; Lawrence, 1991; Young, 1991). Another apomorphy, the location of the thoracic spiracles on a distinct cone-shaped elevation (Fig. 9c), is shared with larvae of Inopeplidae.

A position of Prostomidae within Cucujiformia is clearly confirmed by the presence of tube-like glands in the head (Beutel \& Ślipiński, 2001) and the presence of a mala (Figs 1b, 4d), i.e. the fusion of galea and lacinia, and the strongly reduced condition of the anterior and upper parts of the tentorium (Beutel \& Ślipiński, 2001). The origin of the antennal muscles from the dorsal head capsule (Fig. 71a) is probably correlated with the latter condition.

The monophyly of Tenebrionoidea is not well supported. No autapomorphies based on a comprehensive cladistic analysis are available so far. However, affinities between Prostomidae and other tenebrionoid families are suggested by several presumably apomorphic conditions of their larvae: the gula is well developed, sclerotized and diverges posteriorly (Figs $1 \mathrm{~b}, 2 \mathrm{~b}$ ); gular ridges are present and serve as attachment area of parts of $\mathrm{M}$. tentoriopharyngalis (M. 52) (Fig. 6); the posterior tentorial arms are shifted anteriorly (Fig. 1b), and the labium is narrow and free to the base of the mentum (Figs 1b, 2d). The molar part of the mandible is strongly asymmetric and a prostheca is absent (Fig. 3c, d). These characteristics are not necessarily autapomorphies of the whole superfamily Tenebrionoidea as presently defined (Lawrence \& Newton, 1995), but clearly indicate closer relationships of Prostomidae with tenebrionoid groups than with Cucujoidea (see Beutel \& Ślipiński, 2001). A placement within Cucujoidea as previously suggested is not supported by any potential apomorphies. An apomorphic condition which seems to be autapomorphic for the Cucujoidea + Cleroidea (Beutel \& Ślipiński, 2001), the origin of a part of M. tentoriostipitalis from the posterior hypopharynx, is not found in prostomid larvae.

Among Tenebrionoidea, Prostomidae seem to show closest affinities with the "pythid-pyrochroid-lineage" (= Mycteridae, Boridae, Trictenomatidae, Pythidae, Pyrochroidae, Pedilidae, Othniidae, Salpingidae, Inopeplidae; Lawrence \& Newton, 1982). The articulatory area of the maxilla of larvae of these groups is covered by a pad-like structure (Lawrence, 1991; not distinct in Mycteridae: Pollock et al., 2000) and the abdominal tergite IX extends to the ventral side of the segment (Costa et al., 1988; Lawrence, 1991; Young, 2001; Pollock et al., 2000). The head is always very distinctly prognathous with nearly parallel dorsal and ventral sides of the head. A distinct molar tooth is present on the left mandible of larvae of Prostomidae, Pythidae, Pyrochroidae, Inopeplidae and Othniidae (Young, 1991; Pollock, 1991, 1995; Pollock \& Lawrence, 1995). Larvae of Prostomidae, Boridae, Mycteridae and Pyrochroidae are characterised by a thorax, which is narrower than the head and the abdomen (Lawrence, 1991; Pollock, 1991), and the abdominal segment IX forms a plate-like structure, which articulates 
with segment VIII (Fig. 10e, f) (Lawrence, 1991; Young, 1991; Costa et al., 1998; Pollock et al., 2000). Considering these shared derived features it appears justified to consider prostomid affinities with the "pythid-pyrochroidlineage". A close relationship with Boridae, Mycteridae and Pyrochroidae is strongly suggested by the highly unusual modification of segment IX, a condition which is not found in larvae of other groups of beetles.

The presented phylogenetic hyptheses are preliminary as they are based on a non-cladistic interpretation of characters and an implicit use of cucujoid taxa (see list of taxa examined) as outgroup (Beutel \& Ślipiński, 2001). They will have to be confirmed (or refuted) in future cladistic analyses involving a broad taxon sampling and a broad set of characters.

ACKNOWLEDGEMENTS. We are greatly indebted to. J.F. Lawrence, S.A. Ślipiński (CSIRO, Canberra) and R.A.B. Leschen (New Zealand Arthropod Collection) for gift or loan of valuable specimens. Helpful comments and criticisms by two anonymous reviewers are also gratefully acknowledged. We thank H. Schoppmann (Tübingen) for his skillful work at the SEM, M. Hohloch (Tübingen) for technical assistance, and C. Dietz (Tübingen) for his support during the field work. Part of the study was supported by a grant from the Gottfried und Maria Teufel Stiftung (Tuttlingen) to I. Schunger.

\section{REFERENCES}

Beutel R.G. \& ŚLIPIŃski S.A. 2001: Comparative study of head structures of larvae of Sphindidae and Protocucujidae (Cucujoidea, Coleoptera). Eur. J. Entomol. 98: 219-232.

Böving A.G. \& CRAIGHEAD F.C. 1930: An illustrated synopsis of the principal larval forms of the order Coleoptera. Entomol. Amer. 10: 1-351.

Costa C., Vanin S.A. \& Casari-Chen S.A. 1988: Lavvas de Coleoptera do Brasil. Museo de Zoologia, Universidade de São Paulo, São Paulo, 268 pp.

Costa C., Vanin S.A. \& IDE S. 1995: Larvae of Neotropical Coleoptera XXII. Description of adults and immatures of Lagrioida nortoni sp.n., and bionomics (Coleoptera: Tenebrionoidea, Anthicidae). Iheringia, Sér. Zool., Porto Alegre 78: 113-126.

Crowson R.A. 1953: The classification of the families of British Coleoptera. Entomol. Mon. Mag. 89: 37-59.

Crowson R.A. 1955: The Natural Classification of the Families of Coleoptera. Nathaniel Lloyd, London, $214 \mathrm{pp}$.

Crowson R.A. 1967: The natural classification of the families of Coleoptera, Addenda et Corrigenda. Entomol. Mon. Mag. 103: 209-214.

CurTIS J. 1854: Description of some coleopterous larvae. Trans. Entomol. Soc. London 3: 3-39.

ERICHSON W.F. 1848: Naturgeschichte der Insecten Deutschlands. Erste Abtheilung. Coleoptera, Bd. 3. Verlag der Nicolaischen Buchhandlung, Berlin, 800 pp.

Fleischer A. 1919: Eine neue Prostomis-Art aus dem Elbursgebirge. Entomol. Bl. 15: 211.

HinTON H.E. 1946: The "gin-traps" of some beetle pupae; a protective device which appears to be unknown. Trans. R. Entomol. Soc. Lond. 97: 473-496.
Lawrence J.F. 1977: The family Pterogeniidae, with notes on the phylogeny of the Heteromera. Coleopt. Bull. 31: 25-56.

LAWRENCE J.F. 1991: Mycteridae (Tenebrionoidea) (including Hemipeplidae). Trictenotomatidae (Tenebrionoidea). In: Stehr F.W. (ed.): Immature Insects. Vol. 2. Kendall/Hunt Publishing Company, Dubuque, Iowa, pp. 535-537, 537-541, 544-547.

LAWRENCE J.F. \& NeWTON A.F. jr. 1982: Evolution and classification of beetles. Ann. Rev. Ecol. Syst. 13: 261-290.

Lawrence J.F. \& Newton A.F. jr. 1995: Families and subfamilies of Coleoptera (with selected genera, notes, references, and data on family-group names). In: Pakaluk J. \& Ślipiński S.A. (eds): Biology, Phylogeny, and Classification of Coleoptera: Papers Celebrating the $80^{\text {th }}$ Birthday of Roy $A$. Crowson. Muzeum i Instytut Zoologii PAN, Warszawa, pp. 634-797.

OLIFF A.S. 1884: Description of a new species of Prostomis from Ceylon. Notes Leyden Mus. 6: 100-102.

PoLlock D.A. 1991: Natural history, classification, reconstructed phylogeny, and geographic history of Pytho Latreille (Coleoptera: Heteromera: Pythidae). Mem. Entomol. Soc. Canada 154: 1-104.

Pollock D.A. 1995: Classification, reconstructed phylogeny and geographical history of genera of Pilipalpinae (Coleoptera: Tenebrionoidea: Pyrochroidea). Invertebr. Tax. 9: 563-708.

Pollock D.A. \& Lawrence J.F. 1995: Review of Anaplopus Blackburn (Coleoptera: Pythidae), with comments on constituents and systematics of Pythidae. In: Pakaluk J. \& Ślipiński S.A. (eds): Biology, Phylogeny, and Classification of Coleoptera: Papers Celebrating the $80^{\text {th }}$ Birthday of Roy A. Crowson. Muzeum i Instytut Zoologii PAN, Warszawa, pp. 449-472.

Pollock D.A., Ide S. \& Costa C. 2000: Review of the Neotropical genus Physiomorphus Pic (Coleoptera: Mycteridae: Lacconotinae), with description of the larvae of three species. J. Nat. Hist. 34: 2209-2239.

Rertter E. 1911: Fauna Germanica. Die Käfer des Deutschen Reiches. 3. Band. K. G. Lutz' Verlag, Stuttgart, 436 pp.

SCHawaller W. 1991: Prostomidae (Coleoptera) aus dem Himalaya mit einem Beitrag zur Larvenmorphologie. Stuttg. Beitr. Naturk. (A) 461: 1-17.

Schawaller W. 1992: Prostomidae (Coleoptera) aus SüdostAsien. Rev. Suisse Zool. 99: 255-262.

SChawaller W. 1993: The genus Prostomis (Coleoptera: Prostomidae) in Australia and adjacent regions. Stuttg. Beitr. Naturk. (A) 489: 1-12.

SCHAWAller W. 1994: A new species of Prostomis Latreille from New Caledonia. Doriana 6: 1-3.

VON KÉLER S. 1963: Entomologisches Wörterbuch. AkademieVerlag, Berlin, $679 \mathrm{pp}$.

WILSON J.W. 1930: The genitalia and wing-venation of Cucujidae and related families. Ann. Entomol. Soc. Amer. 23: 305-341.

Young D.K. 1991: Prostomidae (Tenebrionoidea). Boridae (Tenebrionoidea). Pythidae (Tenebrionoidea). Pedilidae (Tenebrionoidea). In: Stehr F.W. (ed.): Immature Insects. Vol. 2. Kendall/Hunt Publishing Company, Dubuque, Iowa, pp. 515-516, 537-541, 544-547.

Received January 15, 2003; revised January 28, 2003; accepted April 11, 2003 